\begin{tabular}{|c|c|}
\hline Title & Hydrophobic Hydrogels with Fruit-Like Structure and Functions \\
\hline Author(s) & $\begin{array}{l}\text { Guo, Hui; Nakajima, T asuku; Hourdet, Dominique; Marcellan, A Iba; Creton, Costantino; Hong, Wei; Kurokawa, } \\
\text { T akayuki; Gong, Jian Ping }\end{array}$ \\
\hline Citation & $\begin{array}{l}\text { A dvanced Materials, 31(25), } 1900702 \\
\text { https://doi.org/10.1002/adma.201900702 }\end{array}$ \\
\hline Issue Date & $2019-06-20$ \\
\hline Doc URL & http:/hdl.handle.net/2115/78650 \\
\hline Rights & $\begin{array}{l}\text { This is the peer reviewed version of the following article: } \\
\text { https://onlinelibrary.wiley .com/doi full/10.1002/adma.201900702, which has been published in final form at } \\
\text { 10.1002/adma.201900702. This article may be used for non-commercial purposes in accordance with Wiley Terms and } \\
\text { Conditions for Self-A rchiving. }\end{array}$ \\
\hline Tyре & article (author version) \\
\hline Additional Information & There are other files related to this item in HUSCAP. Check the above URL. \\
\hline File Information & A dv. Mater. 31(25) 1900702 support. info..pdf \\
\hline
\end{tabular}

Instructions for use 
Supporting Information

\section{Hydrophobic Hydrogels with Fruit-like Structure and Functions}

Hui Guo, Tasuku Nakajima, Dominique Hourdet, Alba Marcellan, Costantino Creton,

Wei Hong, Takayuki Kurokawa, Jian Ping Gong*

Dr. H. Guo, Prof. T. Nakajima, Prof. T. Kurokawa, Prof. J. P. Gong

Laboratory of Soft \& Wet Matter, Faculty of Advanced Life Science, Hokkaido University, N21W11, Kita-ku, Sapporo, Hokkaido, 001-0021, Japan

E-mail: gong@sci.hokudai.ac.jp; Tel \& Fax +81-(0)11-706- 9011.

Dr. H. Guo, Prof. T. Nakajima, Prof. D. Hourdet, Prof. A. Marcellan, Prof. C. Creton, Prof. W. Prof. T. Kurokawa, Prof. J. P. Gong

Global Station for Soft Matter, Global Institution for Collaborative Research and Education (GI-CoRE), Hokkaido University, N21W11, Kita-ku, Sapporo, Hokkaido, 001-0021, Japan

Prof. T. Nakajima, Prof. J. P. Gong

Institute for Chemical Reaction Design and Discovery (WPI-ICReDD), Hokkaido University, N21W10, Kita-ku, Sapporo, Hokkaido, 001-0021, Japan

Prof. D. Hourdet, A. Marcellan, C. Creton

Laboratoire Sciences et Ingénierie de la Matière Molle, ESPCI Paris, PSL University, Sorbonne Université, CNRS, F-75005 Paris, France

Prof. W. Hong

Department of mechanics and aerospace engineering, Southern University of Science and Technology, Shenzhen, Guangdong 518055, P.R. China 


\section{Materials and Methods}

\section{Materials:}

Methyl acrylate (MA), ethyl acrylate (EA), phenyl acrylate (PA), 2-methoxyethyl methacrylate (MEMA) were obtained from Tokyo Chemical Industry Co., Ltd.; hydroxyethyl acrylate (HEA), and acrylamide (AAm) were supplied by Wako Pure Chemical Industries, Ltd.; 2-methoxyethyl acrylate (MEA), tetrahydrofurfuryl acrylate (THFA), ethoxyethoxyethyl acrylate (CBA), benzyl acrylate (BnA), 2-phenoxyethyl acrylate (PHEA), 2-(thio)ethyl acrylate (PHSeA), 2-(2-phenoxyethoxy)ethyl acrylate (PEEA), and tert-butyl acrylate (TBA) were kindly provided by Osaka Organic Chemical Industry Ltd.. Crosslinking agents $N, N^{\prime}$-methylenebisacrylamide (MBA, Wako Pure Chemical Industries, Ltd.), butanediol diacrylate (BDA, Tokyo Chemical Industry Co., Ltd), poly(ethylene glycol) diacrylate (PEGDA, Mw 250, Sigma-Aldrich Corporation), and photo-initiator 2-oxoglutaric acid ( $\alpha$-keto) (Wako Pure Chemical Industries, Ltd.) were used as received. All organic solvents were analytical grade and water was purified with a Millipore system combining inverse osmosis membrane (Milli RO) and ion exchange resins (Milli Q) for synthesis, purification and swelling test.

\section{Preparation of organo-gels:}

All organo-gels, unless otherwise specified, were prepared by crosslinking polymerization in DMSO using an initial monomer concentration of $20 \mathrm{wt} \%$ with MBA ( $1 \mathrm{~mol} \%$ to monomer) as crosslinking agent. Typical PMA organo-gel is taken for example to illustrate the preparation of both organo-gels and hydrogels. PMA-DMSO organo-gels were synthesized by free-radical polymerization initiated by UV light. MA monomer, $1 \mathrm{~mol} \%$ of MBA and $0.14 \mathrm{~mol} \%$ of $\alpha$-keto with respect to MA, were dissolved in DMSO solution (MA concentration equal to $20 \mathrm{wt} \%$ of the 
solution) and deoxygenated under argon atmosphere. Then, always under argon atmosphere, the solution was poured at room temperature between two glass plates, separated by silicone rubber spacer with thickness of 0.5-5 mm. Photo-polymerization was carried out by $365 \mathrm{~nm}$ UV irradiation for $8 \mathrm{~h}$ at $25^{\circ} \mathrm{C}$ under argon atmosphere. After polymerization, the as-prepared organo-gels were immersed in a large amount of DMSO for 3 days. During this process, DMSO was exchanged once per day to reach a thermodynamic equilibrium state and wash away any residual chemicals. For organo-gels equilibrated with other organic solvents, the as-prepared PMA-DMSO organo-gel were immersed in given solvent for 3 days with frequent solvent exchange, until no detectable DMSO residue left.

\section{Hydrogels Preparation and Swelling Ratio Measurement:}

After reaching equilibrated states in defined organic solvent, organo-gels were cut into a defined shape and immersed in a large amount of aqueous solution (typically pure water; the amount of aqueous solution is generally 100 times that of the organo-gels in weight). During immersion, the aqueous solution was changed frequently at $1 \mathrm{~h}, 2 \mathrm{~h}, 4 \mathrm{~h}, 8 \mathrm{~h}, 24 \mathrm{~h}$ for the first day and once per day thereafter while the weight of the sample was recorded at specific time. Unless otherwise specified, organo-gels with discoid geometry of initial thickness $(t)=2.0 \mathrm{~mm}$, diameter $(\mathrm{d})=35$ $\mathrm{mm}$ were used for the experiments. During the swelling process, the weight of swollen gel in aqueous media $\left(\mathrm{m}_{\mathrm{a}}\right)$ and the equilibrium gel in the organic solvent $\left(\mathrm{m}_{\mathrm{o}}\right)$ were obtained. The swelling ratio (q) of the gels was defined as the weight ratio of $\mathrm{m}_{\mathrm{a}} / \mathrm{m}_{\mathrm{o}}$. At least three distinct essays were performed to get the mean value and standard deviation.

\section{Uniaxial Tensile Test:}


Uniaxial tensile experiments were performed at $25{ }^{\circ} \mathrm{C}$ in air with humidifier using a commercial testing machine (Instron 5965 type universal testing system). PMA organo-gels were used directly at swelling equilibrium state and PMA hydrogels were applied by immersing corresponding organo-gels (initial thickness $=2.0 \mathrm{~mm}$ ) in water for $8 \mathrm{~h}$. Samples were cut into the dumbbell shape standardized as JIS K6251-7 (test region: width $=2 \mathrm{~mm}$, length $=12 \mathrm{~mm}$, with a cutting machine specially designed for soft materials (SDAP-100 N, Dumbbell Co., Ltd.). Both ends of a test piece were clamped and pulled apart at a constant velocity of $100 \mathrm{~mm} \cdot \mathrm{min}^{-1}$. The fracture stress and the fracture strain were defined as the nominal stress and strain at breaking point, respectively and Young's modulus was defined as the slope of the initial stress-strain curves.

\section{${ }^{1} \mathrm{H}$ Nuclear Magnetic Resonance ( ${ }^{1} \mathrm{H}$ NMR):}

All the measurements were performed on Oxford NMR AS500 spectrometer operating at $500 \mathrm{MHz}$ for ${ }^{1} \mathrm{H}$, using a standard $5 \mathrm{~mm}$ broadband Smart probe at $25{ }^{\circ} \mathrm{C}$, with 32 transients, 45-degree flip angle, $2.5 \mathrm{sec}$ acquisition time and $2 \mathrm{sec}$ relaxation delay.

\section{Gas Chromatography (GC):}

Organic solvent residues were verified by gas chromatography (GC) (Shimadzu GC-2014), using a Shimadzu SH-Rtx-624 (30 m - $0.25 \mathrm{~mm})$ column and flame ionization detector with ultra pure helium carrier gas. The column temperature was first kept from 60 to $200{ }^{\circ} \mathrm{C}$ with heating rate of $10{ }^{\circ} \mathrm{C} \cdot \mathrm{min}^{-1}$ and remained at $200{ }^{\circ} \mathrm{C}$ for another $10 \mathrm{~min}$. The temperatures of the injector and detector were maintained at 220 and $250^{\circ} \mathrm{C}$, respectively.

\section{Scanning Electron Microscope (SEM):}


The cross-section structure of the gels in freeze-dried state was observed by scanning electron microscopy (SEM, JSM-6010LA, JEOL Ltd.). Poly(phenyl acrylate) (PPA)-DMSO gels swollen in water for 40 days were cooled in liquid nitrogen for several minutes where their structures were rapidly frozen, and then fractured mechanically by the sample holder. The dehydrated samples kept the same sizes as those before drying. Prior to SEM observation, the surface was coated with a thin layer of gold by sputtering method. The samples were fixed to the substrate with carbon tape, and then subjected to SEM observation under a low vacuum pressure mode.

\section{Static Water Contact Angle Measurement on hydrogel surfaces:}

All water contact angles were measured on the DropMaster 300 Contact Angle Measuring System. A $2.0 \mu \mathrm{L}$ water droplet was carefully deposited on hydrogels surfaces using a hydrophobized syringe. At least three different spots on the same sample surface were taken for contact angle measurements to obtain a mean value.

\section{Measurement of Residual Organic Solvent:}

The residual organic solvents within bulk hydrogels were measured by GC. Swollen hydrogels samples with an initial organic solvent amount (v0) were taken out from water at designed time and soaked in large amount of acetone to re-swell the hydrogels and extract the trapped solvent prior to test. Then the volume of organic solute $\left(\mathrm{v}_{\mathrm{r}}\right)$ was obtained using an external standard method by comparing the area with solvent peak. Subsequently, the residual organic solvent ratio was calculated based on the equation $\mathrm{v}_{\mathrm{r}} / \mathrm{V}_{0} * 100 \%$. At least three separately essays are performed to get the mean value and standard deviation.

\section{Determination of Partition Coefficient:}


The partition coefficient measurement was carried out in a two-phase solvent system comprising almost immiscible solvents hydrophobic monomer $(4 \mathrm{~mL})$ and water $(4 \mathrm{~mL})$. After the addition of small amount of tested organic solvent $(0.1 \mathrm{~mL})$, the liquids were mixed by vigorous shaking for $1 \mathrm{~h}$. After stabilized at room temperature for $24 \mathrm{~h}$, the concentration of organic solvent in both phases was measured respectively by ${ }^{1} \mathrm{H}$ NMR and the partition coefficient were calculated as the ratio between the organic solvent amount in monomer phase over that in the aqueous phase. Three separately essays were performed to get the mean value and standard deviation.

\section{Water Retention Test:}

Water retention capability was evaluated by measuring water mobility during dynamic deswelling test. Hydrogels at maximum swelling states (water content $~ 99$ $\mathrm{wt} \%$, sample thickness $=4.0 \mathrm{~mm}$, diameter $=50 \mathrm{~mm}$ ) were placed in a fume hood at 25 ${ }^{\circ} \mathrm{C}$ and weighed at regular intervals. The weights of fully swollen hydrogels $\left(\mathrm{m}_{\mathrm{s}}\right)$, hydrogels at time $t\left(\mathrm{~m}_{\mathrm{t}}\right)$, and dry sample $\left(\mathrm{m}_{\mathrm{d}}\right)$ were recorded. The deswelling profile could be presented by plotting residual water versus time, where the residual water ratio $=\left(\mathrm{m}_{\mathrm{t}}-\mathrm{m}_{\mathrm{d}}\right) /\left(\mathrm{m}_{\mathrm{s}}-\mathrm{m}_{\mathrm{d}}\right) * 100 \%$.

\section{Water Recovery Tests:}

Water recovery test was calculated by measuring the water of hydrogels at fully swollen state $\left(\mathrm{m}_{1}\right)$ and after undergoing squeezing process $\left(\mathrm{m}_{2}\right)$. Typically, PMA hydrogels at maximum swelling state (sample thickness $=3.0 \mathrm{~mm}$, diameter $=32 \mathrm{~mm}$ ) were submitted to a normal compressive stress around $0.5 \mathrm{MPa}$ for 2 min to fulfill the squeezing process. Then the water content after that was defined as $\left(\mathrm{m}_{2} / \mathrm{m}_{1}\right)^{*} 100 \%$, while $100 \%$ water content value is assumed before freezing test. PMA organo-gels 
were prepared with $20 \%$ initial monomer concentration and $0.3 \mathrm{~mol} \%$ of MBA for this purpose.

\section{A sandwich structure model for evolution of anisotropic swelling in water}

We consider swelling of a thin sheet. The diffusion from the periphery of the sheet is negligible, and we only need to consider the diffusion from the two surfaces of the sheet.

We consider a small rectangular piece of sample with length $d$ and thickness $t$ at the initial state (Figure S7b). After a given swelling time, we assume that the top and bottom layers swell while the middle one is still unswelled, and the swollen layer has an initial thickness $\mathrm{t}_{1}$ and the unswollen middle layer has an initial thickness $\mathrm{t}_{2}$, then,

$\mathrm{t}=2 \mathrm{t}_{1}+\mathrm{t}_{2}$

The initial volumes of the swollen and unswollen layers, are, respectively,

$\mathrm{V}_{1}=(\mathrm{d})^{2 * \mathrm{t}_{1}}$

$\mathrm{V}_{2}=(\mathrm{d})^{2 * \mathrm{t}_{2}}$

After swelling, the length of the piece sheet become d', and the thickness turn to t 1 ', $t_{2}$ ' and 't'. The volumes of each swollen layer and unswollen layer becomes, respectively,

$\mathrm{V}_{1}{ }^{\prime}=\mathrm{d}^{\prime 2} *_{\mathrm{t}_{1}}$,

$\mathrm{V}_{2}{ }^{\prime}=\mathrm{d}^{2}{ }^{2} \mathrm{t}_{2}{ }^{\prime}$

If the swelling ratio of the swollen layer is $\mathrm{q}_{1}$, then

$\mathrm{V}_{1}{ }^{\prime}=\mathrm{V}_{1}{ }^{*} \mathrm{q}_{1}$

Since the gel is uncompressible, the unswollen layer

$\mathrm{V}_{2}{ }^{\prime}=\mathrm{V}_{2}$

Thus,

$\mathrm{t}_{1}{ }^{\prime}=(\mathrm{d})^{2 *} \mathrm{t}_{1} * \mathrm{q}_{1} / \mathrm{d}^{\prime 2}$ 
$\mathrm{t}_{2}{ }^{\prime}=(\mathrm{d})^{2 *} \mathrm{t}_{2} / \mathrm{d}^{\prime 2}$

Then the final thickness

$\mathrm{t}^{\prime}=2 \mathrm{t}_{1}{ }^{\prime}+\mathrm{t}_{2}{ }^{\prime}=\left(2 \mathrm{q}_{1} \mathrm{t}_{1}+\mathrm{t}_{2}\right)^{*} \mathrm{~d}^{2} / \mathrm{d}^{\prime 2}$

If the anisotropy is defined as $\mathrm{A}=\left(\mathrm{d}^{\prime} / \mathrm{d}\right) /\left(\mathrm{t}^{\prime} / \mathrm{t}\right)$,

$A=\left(\frac{d \ell}{d_{0}}\right)^{3} \frac{2 t_{1}+t_{2}}{2 q_{1} t_{1}+t_{2}}$

Without the interfacial connection, the swollen layers swell isotropically, and the unswollen layer remains unchanged. Then the ideal thickness $\left(t_{1 i}\right)$ and diameter $\left(d_{i}\right)$ of swollen layer:

$\mathrm{t}_{1 i}=\mathrm{t}_{1} * \mathrm{q}_{1}{ }^{1 / 3}$

$\mathrm{di}_{\mathrm{i}}=\mathrm{d}^{*} \mathrm{q}_{1}{ }^{1 / 3}$

However, the swelling mismatch of 3 layers generates a stretch on the unswollen layer, while a compresses on the swollen layers along the direction parallel to the surface of the sheet. Then we denote $\mathrm{F}$ as the biaxial compressive force exerted on one swollen layer from the unswollen layer, then the unswollen layer suffers a biaxial tensile force of $2 \mathrm{~F}$ from the two swollen layers. The initial elastic moduli in the equal biaxial mode of swollen and unswolllen layers are $E_{1}$ and $E_{2}$, respectively. Then, for the unswollen layer,

$2 \mathrm{~F}=\mathrm{E}_{2} * \frac{\mathrm{d}^{f}-\mathrm{d}_{\mathrm{d}}}{\mathrm{d}} \mathrm{t}_{2} \mathrm{~d}$

For the swollen layer,

$\mathrm{F}=\mathrm{E}_{1} *\left(\frac{\mathrm{d}_{1}-\mathrm{d} t}{\mathrm{~d}_{1}}\right) \mathrm{t}_{1 \mathrm{i}} \mathrm{d}_{\mathrm{i}}=\mathrm{E}_{1} *\left(\frac{\mathrm{dq}_{1}^{1 / 2}-\mathrm{d} t}{\mathrm{~d} * \mathrm{q}_{1}^{1 / 3}}\right) \mathrm{t}_{1} \mathrm{dq}_{1}^{2 / 3}$

Combining equations S14 and S15,

$\frac{\mathrm{d} \epsilon}{\mathrm{d}}=\frac{\mathrm{q}_{1}^{2 / 3}+\frac{\mathrm{E}_{2} \mathrm{t}_{2}}{2 \mathrm{E}_{2} \mathrm{t}_{1}}}{\mathrm{q}_{1}^{1 / 3}+\frac{\mathrm{E}_{2} \mathrm{t}_{2}}{2 \mathrm{E}_{1} \mathrm{t}_{1}}}$

If $\mathrm{q}$ is the swelling ratio of the whole sample, 
$\mathrm{q}=\left(2 \mathrm{q}_{1} \mathrm{~V}_{1}+\mathrm{V}_{2}\right) /\left(2 \mathrm{~V}_{1}+\mathrm{V}_{2}\right)$

Combining the equations S2, S3 with S17,

$\mathrm{q}=\frac{2 \mathrm{q}_{1} \mathrm{t}_{1}+\mathrm{t}_{2}}{2 \mathrm{t}_{1}+\mathrm{t}_{2}}$

Then, the equation S11 turned to

$\mathrm{A}=\left(\frac{\mathrm{q}_{1}^{2 / 3}+\frac{\mathrm{E}_{2} \mathrm{t}_{2}}{2 \mathrm{E}_{1} \mathrm{t}_{1}}}{\mathrm{q}_{1}^{1 / 3}+\frac{\mathrm{E}_{2} \mathrm{t}_{2}}{2 \mathrm{E}_{1} \mathrm{t}_{1}}}\right)^{3} \mathrm{q}^{-1}=\left(\frac{\mathrm{q}_{1}^{2 / 3}+\frac{\mathrm{E}_{2}\left(\mathrm{q}_{1}-\mathrm{q}\right)}{\mathrm{E}_{1}(\mathrm{q}-1)}}{\mathrm{q}_{1}^{1 / 3}+\frac{\mathrm{E}_{2}\left(\mathrm{q}_{1}-\mathrm{q}\right)}{\mathrm{E}_{1}(\mathrm{q}-1)}}\right)^{3} \mathrm{q}^{-1}$

Based on this equation, the anisotropicity is only determined by q, $\mathrm{q}_{1}$, and $\mathrm{E}_{2} / \mathrm{E}_{1}$., where q has been alrealy obtained experimentally (Figure 1e). By making a best fitting of our experimental data of A vs. q at various times, we obtained the fitted values of $\mathrm{q}_{1}=8$ and $\mathrm{E}_{2} / \mathrm{E}_{1}=0.6$. The value of $\mathrm{q}_{1}$ is finely reasonable if assuming that the swollen layers are totally swollen. Meanwhile, we should also take into account that the two layers are formed with gradient, thus the modulus difference of $E_{2} / E_{1}=0.6$ is plausible. Then we get a fitting curve in Figure 3e, which is in good accordance with experimental data.

Combing equation S8, S10 and S17, the fraction of swollen thickness:

$2 \frac{\mathrm{t}_{1 /}}{\mathrm{t} t}=\frac{(\mathrm{q}-1) \mathrm{q}_{1}}{\mathrm{q}\left(\mathrm{q}_{1}-1\right)}$

Then, from the time $\sim$ q dependence from Figure 1e, we get a fitting curve of the time dependence of the fraction of swollen layer thicknes by using equation S20 (Figure S7c), which is in good agreement with experimental observation. The deviation of fitting at initial swelling state is probably related to the ignored effect of surface skin layers, which should play an important role at the beginning of swelling 


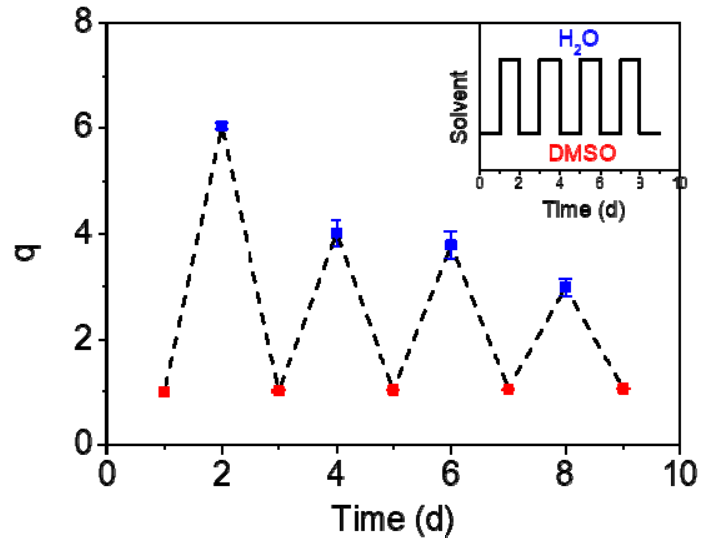

Figure S1 The swelling repeatability of PMA gels in water and "swelling solvent" $\mathrm{DMSO}$ at $25^{\circ} \mathrm{C}$. The procedures of DMSO-water exchange is illustrated in the inset.

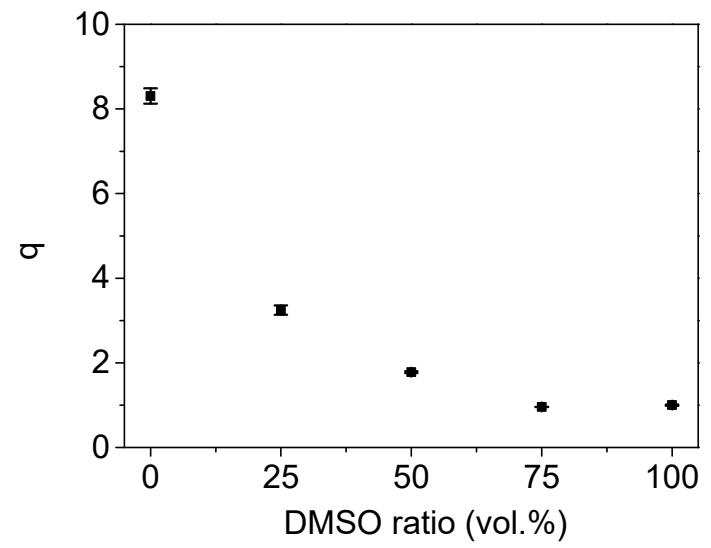

Figure S2 Maximum swelling ratio q of PMA organo-gel in different ratio of DMSO-water cosolvent at $25{ }^{\circ} \mathrm{C}$. Organo-gels with same initial geometry (thickness $=2.0 \mathrm{~mm}$; diameter $=35 \mathrm{~mm}$ ) were applied for the measurements.

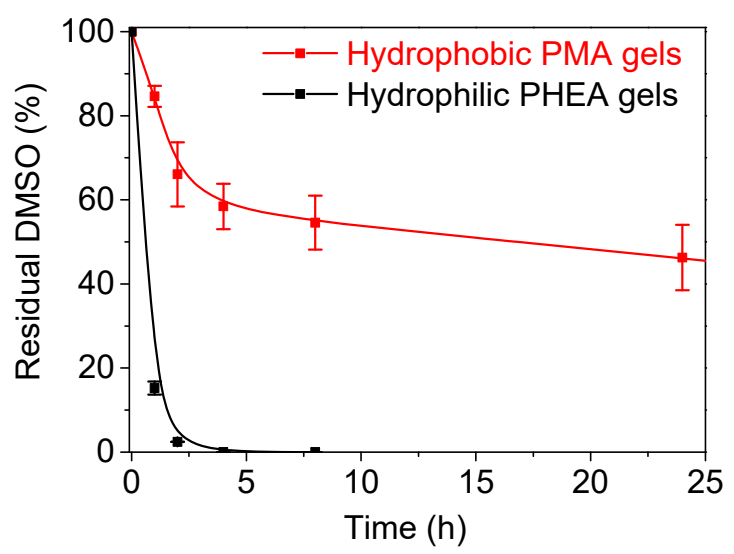

Figure S3 Residual DMSO amount in hydrophobic PMA and hydrophilic PHEA organo-gels after being immersed in water at $25^{\circ} \mathrm{C}$. 


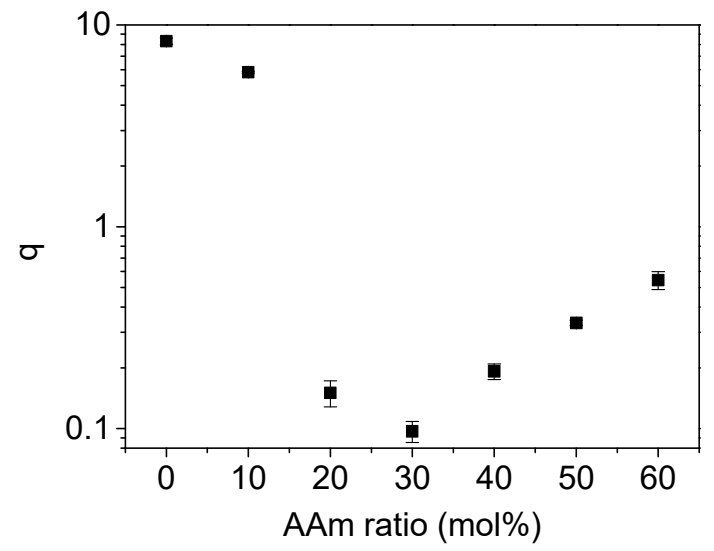

Figure S4 Maximum swelling ratio q of different organo-gels in DMSO and pure water at $25{ }^{\circ} \mathrm{C}$. Organo-gels were prepared by copolymerization of MA with different molar ratio of hydrophilic monomer AAm (Acrylamide) with 1 mol\% of crosslinker MBA.
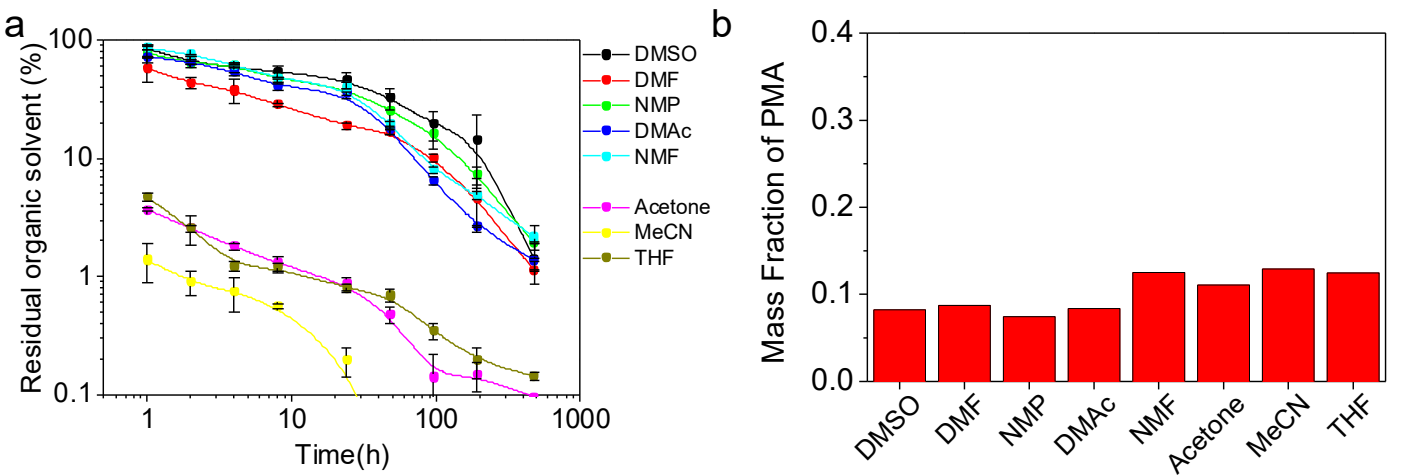

Figure S5 Influence of the organic solvent. (a) Time dependence of the residual organic solvent content in PMA hydrogels. Organo-gels with the same initial geometry (thickness $=2.0 \mathrm{~mm}$; diameter $=35 \mathrm{~mm}$ ) were used for the measurement. (b) Equilibrated mass fraction of PMA polymer in different organic solvents.
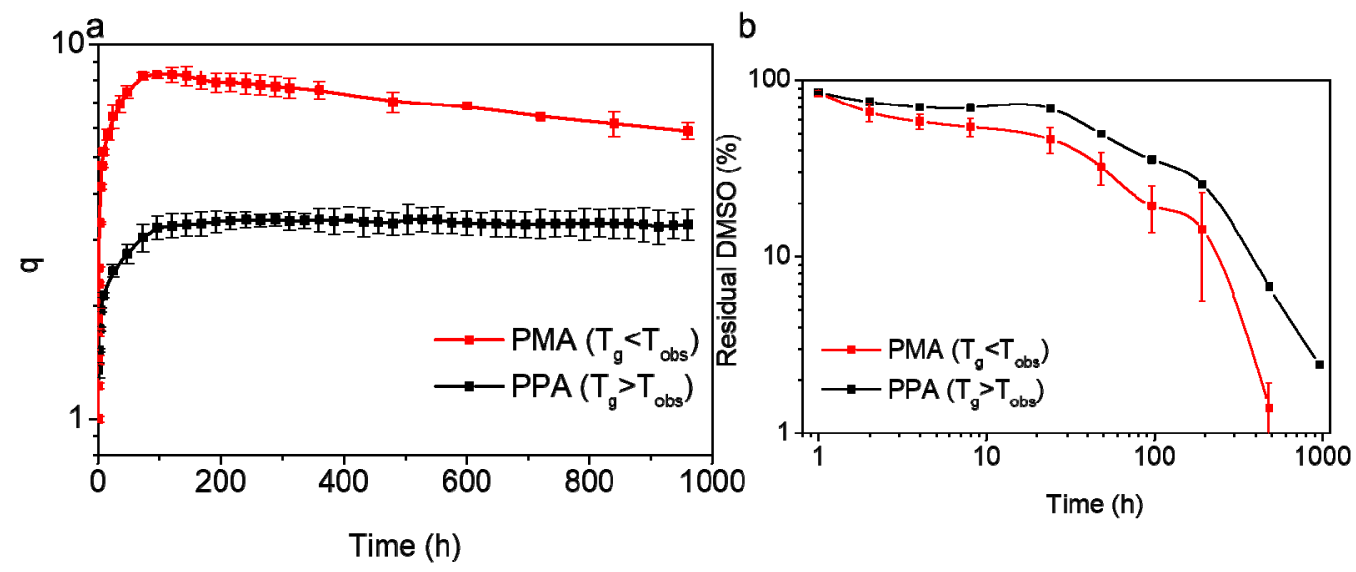

Figure S6 Influence of polymer Tg on the swelling behavior of organo-gels. (a) Swelling kinetics of DMSO swollen PMA ( $\left.\mathrm{T}_{\mathrm{g}}<\mathrm{T}_{\mathrm{obs}}\right)$ and PPA $\left(\mathrm{T}_{\mathrm{g}}>\mathrm{T}_{\mathrm{obs}}\right)$ organo-gels in water at $\mathrm{T}_{\mathrm{obs}}=25^{\circ} \mathrm{C}$. (b) The corresponding time profiles of residual DMSO in the samples. 
a

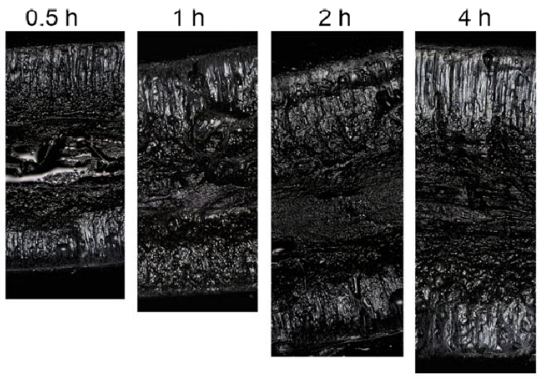

$1 \mathrm{~mm}$
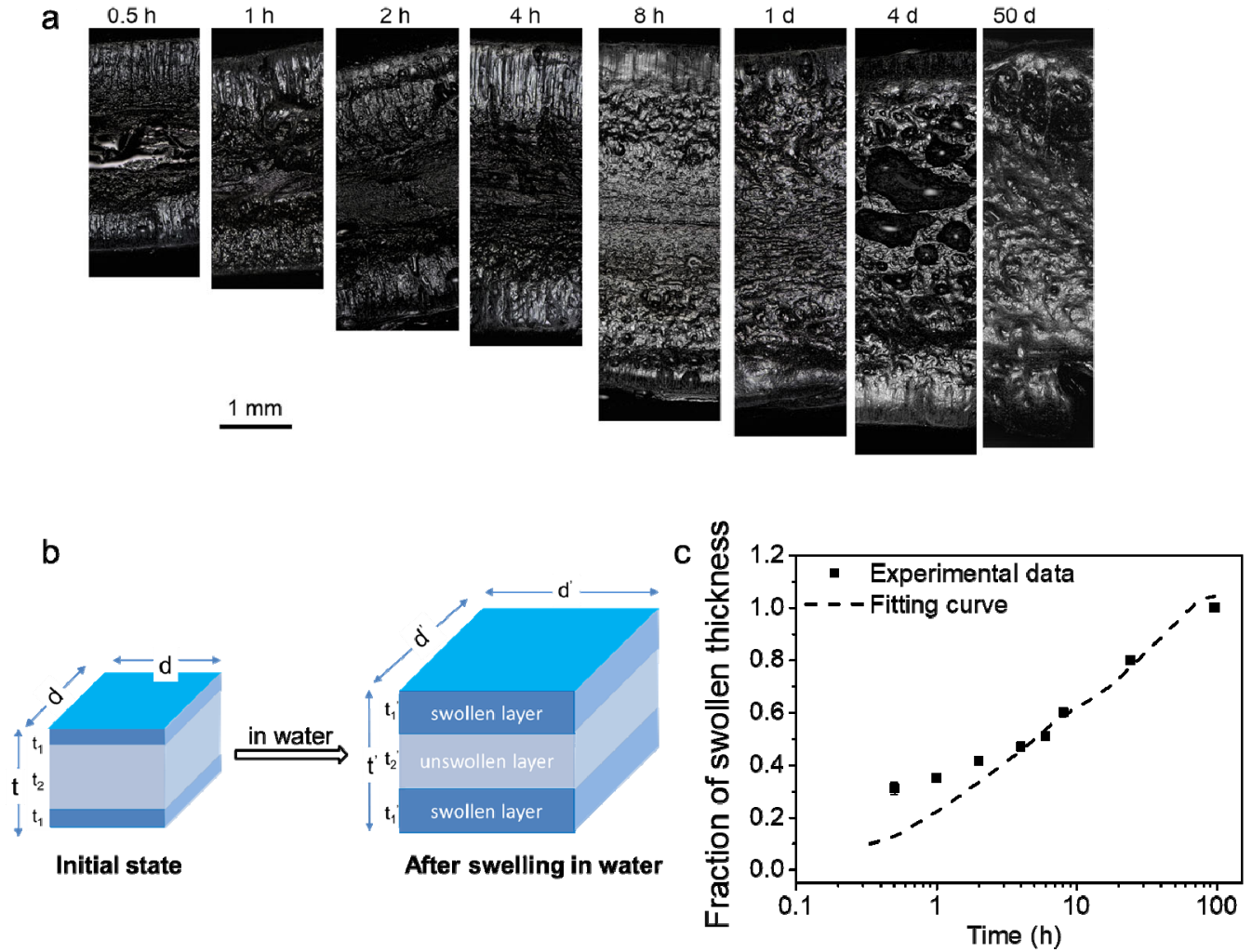

Figure S7 (a) 3-D laser microscope images showing the time evolution of the cross-section of PMA hydrogels during swelling in water. The immersing time is given above the photograph. Organo-gels with the same initial geometry (thickness $=2.0 \mathrm{~mm}$, diameter $=35 \mathrm{~mm}$ ) as that shown in Figure $3 \mathrm{~b}-\mathrm{c}$ were used for the test. (b) Illustration of the layered structure formed during swelling for a small element in a disc shape sample. (c) Time profiles of fraction of swollen thickness determined from (a). The dash line is the prediction from the sandwich structure model using Equation S20. Fraction of swollen thickness is defined as the total thickness of the two swollen layers on surface sides divided by the whole thickness of the sample $\left(2 \mathrm{t}_{1}{ }^{\prime} / \mathrm{t}^{\prime}\right)$ at the corresponding times.

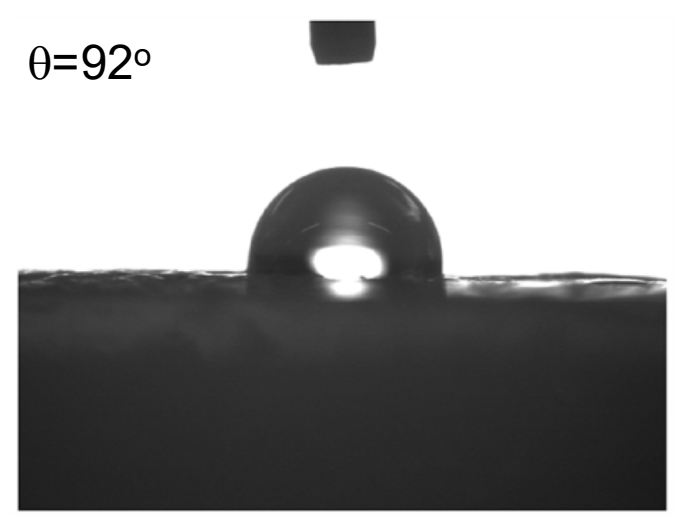

Figure S8 Static contact angle of a water droplet on the surface of a PMA hydrogel. The PMA hydrogel was obtained by swelling PMA-DMSO gel in water for 4 days. 